\title{
Assessment of the effect of oral corticosteroids on bone mineral density in systemic lupus erythematosus: a preliminary study with dual energy $x$ ray absorptiometry
}

V B Dhillon, M C Davies, M L Hall, J M Round, P J Ell, H S Jacobs, M L Snaith, D A Isenberg

\begin{abstract}
Dual energy $x$ ray absorptiometry and a wide range of blood and urine tests were used to assess the propensity of patients with systemic lupus erythematosus to develop an impairment of bone mineral density. Surprisingly, in this preliminary study no significant differences in bone mineral density were found when patients taking $10 \mathrm{mg}$ or more of prednisolone for six months or longer were compared with those who had never taken prednisolone.
\end{abstract}

Systemic lupus erythematosus (SLE) predominantly affects women in their reproductive years. ${ }^{1}$ The female to male ratio is about $9: 1 .^{2}$ It is often necessary to treat the disease with oral corticosteroids for prolonged periods of time.

Active SLE is also associated with menstrual irregularity, notably amenorrhoea. ${ }^{3}$ Amenorrhoea may be associated with oestrogen deficiency. ${ }^{4}$ Both glucocorticoid treatment ${ }^{5}$ and oestrogen deficiency ${ }^{6}$ are associated with the development of osteoporosis, which may be defined as a reduction in bone mass below that expected for age and sex, and which has been shown to be related causally to an increased risk of lumbar spine and femoral neck fractures. These fractures are a significant cause of mortality and morbidity among the 'normal' female population. ${ }^{4}$ Among lupus patients increased morbidity occurs for many reasons-for example, bleeding when patients are taking oral anticoagulants to treat thrombotic problems associated with anticardiolipin antibodies, skin ulceration, and poor healing because of vasculitis resulting in suboptimal outcome of fracture treatment.

Given these concerns and the recent availability of dual energy $x$ ray absorptiometry, a significant advance in the assessment of bone mineral density, ${ }^{8}$ we designed a study to determine the effect of oral corticosteroids on bone mineral density in patients with SLE. The patients were subdivided into those receiving regular oral corticosteroids, those who had never taken steroids, a disease control group receiving regular steroids, and a healthy control group. Pathology, UCMSM, London

J M Round

Correspondence to: Dr D A Isenberg, Bloomsbury Rheumatology Unit, Arthur Stanley House, 40-50 Tottenham Street, London WIP 9PG.

Accepted for publication 21 September 1989 PATIENTS

Thirty six premenopausal women were studied. They were divided into four groups with the following inclusion criteria:

Group $1(\mathrm{n}=12)$ consisted of patients with
SLE who had been taking oral prednisolone at a dose of at least $10 \mathrm{mg}$ a day for at least six months.

Group $2(n=10)$ consisted of patients with SLE who had never received treatment with prednisolone.

Group $3(\mathrm{n}=4)$-the disease control group, comprised patients with chronic asthma, using glucocorticoids in the same dose and for the same length of time as those in group 1.

Group $4 \quad(\mathrm{n}=10)$-normal control group matched for age.

All patients with SLE fulfilled the American Rheumatism Association's revised criteria for the diagnosis of $\mathrm{SLE}^{9}{ }^{9}$ and were regularly followed up at the Bloomsbury rheumatology unit. The patients with asthma were recruited from chest clinics at the Middlesex and University College Hospitals, and from the patient self help Steroid Aid Group. The normal control group was recruited from members of hospital and laboratory staff.

The single exclusion criterion was known renal impairment, to avoid the confounding factors of secondary hyperparathyroidism with altered calcium balance and renal osteodystrophy.

\section{MEASUREMENTS}

Bone mineral density (BMD) was measured by dual energy $x$ ray absorptiometry using the Hologic QDR-1000 densitometer.

In this study BMDs of lumbar vertebrae 1 to 4 were measured and the mean value presented, expressed in $\mathrm{g} / \mathrm{cm}^{2}$.

Disease activity of the lupus patients was assessed with the UCH/Middlesex SLE scoring system, ${ }^{10}$ which takes into account clinical, biochemical, haematological, and therapeutic indices as well as a visual analogue score of the patient's own perception of wellbeing. A numerical score of disease activity is obtained, which is graded from 1 to 4 (inactive to severely active disease). This system has recently been validated with a more complex computer based index (BILAG). ${ }^{11}$

Background information was obtained by a detailed questionnaire (available from the authors). Information was elicited about the subject's dietary habits, medical history, mobility, therapeutic history, and menstrual history.

Blood samples were obtained in the early to midfollicular phase of the menstrual cycle. Plasma urea, electrolyte, calcium, liver enzyme, serum oestradiol $11 \beta$, and gonadotrophin concentrations were measured. 
Table 1: Baseline data for groups 1 to 4. Mean results with standard deviations in parentheses

\begin{tabular}{lccccc}
\hline Group & Number & $\begin{array}{l}\text { Height } \\
(\mathrm{m})\end{array}$ & $\begin{array}{l}\text { Weight } \\
(\mathrm{kg})\end{array}$ & $\begin{array}{l}\text { BMI*} \\
\left(\mathrm{kg} / \mathrm{m}^{2}\right)\end{array}$ & $\begin{array}{l}\text { Age } \\
\text { (years })\end{array}$ \\
\hline 1 & 12 & $1 \cdot 61$ & $58 \cdot 2$ & $22 \cdot 47$ & 35 \\
2 & 10 & $(0 \cdot 08)$ & $(8 \cdot 7)$ & $(3 \cdot 26)$ & $(8 \cdot 5)$ \\
3 & $1 \cdot 60$ & $59 \cdot 5$ & $23 \cdot 19$ & 34 \\
& 4 & $(0 \cdot 05)$ & $(10 \cdot 1)$ & $(2 \cdot 44)$ & $(10 \cdot 8)$ \\
4 & 10 & $(0 \cdot 59$ & $57 \cdot 9$ & $22 \cdot 72$ & 40 \\
& & $1 \cdot 66$ & $(20 \cdot 9)$ & $(7 \cdot 14)$ & $(9 \cdot 5)$ \\
& & $(0 \cdot 05)$ & $(9 \cdot 6)$ & $22 \cdot 25$ & 35 \\
& p NS & p NS & p NS & p NS \\
\hline
\end{tabular}

${ }^{*} \mathrm{BMI}=$ body mass index.

Twenty four hour urine samples were obtained. Urinary calcium, creatinine, and total hydroxyproline excretions were measured: urinary calcium was measured by atomic absorption spectrophotometry; urinary creatinine by a Beckman A58 analyser (Jaffe reaction), and total hydroxyproline by the method of Coward, Sawyer, and Whitehead. ${ }^{12}$ These values were expressed as a calcium/creatinine ratio and a total hydroxyproline/creatinine ratio respectively. Creatinine clearance was also calculated.

\section{Results}

Table 1 shows the the subject groups were matched for age, height, weight, and body mass index (weight/height ${ }^{2}$ ). They were also matched for race. Mean values were compared by one way analysis of variance. Numbers in the disease control group 3 were small because of the difficulty of recruiting young female patients with asthma who had been treated with steroids for a long time.

The figure shows BMDs of all patients, together with means and standard deviations (SD), classified by their groups. The normal range of BMD in this study was 0.837 to 1.253 (mean for group $4 \pm 2$ SD). None of the group 1 patients had osteoporosis, nor had a BMD which fell outside the above range.

Two patients in the study had osteoporosis (defined arbitrarily as a BMD more than 2 SD below the mean for a given age group). One of these patients was in group 2 and was one of the oldest study patients (51 years) but still with regular menses, who smoked heavily; the other was a patient in group 3 with a BMD of 0.579 . This patient was a 26 year old Asian with a body

Bone mineral densities of all subjects, with mean and standard deviation (SD), classified by group.

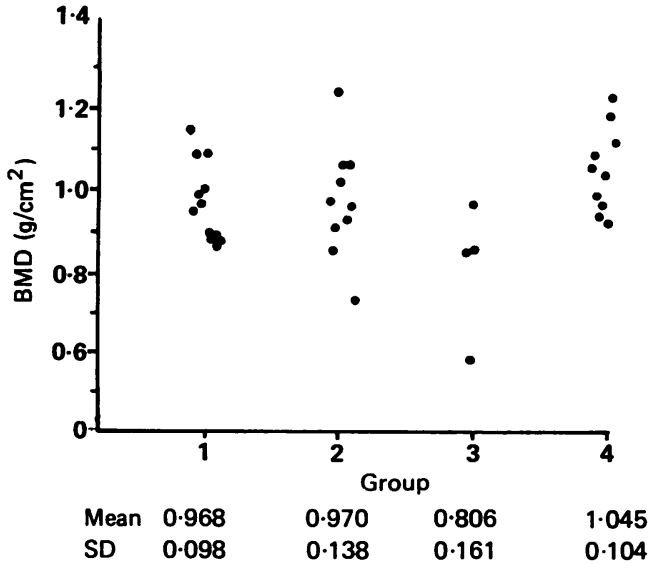

Table 2: Urinary biochemical data

\begin{tabular}{llll}
\hline Group & $\begin{array}{l}\text { THP*/creatinine } \\
\text { ratio }\end{array}$ & $\begin{array}{l}\text { Calcium/creatinine } \\
\text { ratio }\end{array}$ & $\begin{array}{l}\text { Creatinine } \\
\text { clearance } \\
\text { (ml/min)t }\end{array}$ \\
\hline 1 & $0.02(0.01)$ & $0 \cdot 22(0 \cdot 17)$ & $94(25)$ \\
2 & $0.02(0)$ & $0.36(0 \cdot 12)$ & $110(13)$ \\
3 & $0.01(0.01)$ & $0.57(0 \cdot 36)$ & $74(26)$ \\
4 & $0.02(0.01)$ & $0.34(0 \cdot 18)$ & $106(29)$ \\
& p NS & p NS & p NS \\
\hline
\end{tabular}

*THP=total hydroxyproline.

†Normal range $70-145 \mathrm{ml} / \mathrm{min}$.

mass index of $16 \cdot 08$, but who also had regular menses. No vertebral fractures were shown by dual energy $x$ ray absorptiometry in the study patients.

As shown in table 2 all the lupus patients had normal renal function as assessed by creatinine clearance. Similarly, mean calcium and total hydroxyproline excretion did not differ significantly in groups 1 and 2 compared with group 4.

Table 3 shows the general mobility of each group as assessed by the subjects' acknowledged ability to perform activities of daily living. Mobility was significantly reduced in group 1 compared with groups 2 and 4 . Similarly, group 3 subjects had significantly reduced mobility compared with group 4 . There was no significant difference in mobility between groups 2 and 4 (Fisher's exact test). This is an expected finding in patients who have disease which is severe enough to warrant steroid treatment.

Mean disease activity grade was significantly higher in group 1 than in group 2 (table 4). Four patients in group 1 had irregular menstrual cycles, and three of these patients had been amenorrhoeic intermittently for the previous three years. There were no patients with menstrual irregularity in groups 2 or 3 , and one in group 4. These differences did not reach statistical significance.

Correlation coefficients were calculated, and no correlation was found between BMD and the following variables: height, weight, body mass index, age, disease activity, disease duration, duration of steroid treatment, dose of steroid, oestradiol concentrations, smoking, alcohol intake, drug treatment (oral contraceptive pill use, calcium and vitamin D supplementation), and number of hours of weekly exercise.

Table 3: General mobility

\begin{tabular}{|c|c|c|c|c|c|c|}
\hline \multirow[t]{2}{*}{ Group } & \multicolumn{5}{|c|}{$\begin{array}{l}\text { Activities of daily living } \\
\text { limited by disease: }\end{array}$} & \\
\hline & $\overline{Y e s}$ & No & Don't kn & & & \\
\hline $\begin{array}{l}1 \\
2 \\
3 \\
4\end{array}$ & $\begin{array}{l}7 \\
1 \\
4 \\
0\end{array}$ & $\begin{array}{r}3 \\
7 \\
0 \\
10\end{array}$ & $\begin{array}{l}2 \\
2 \\
0 \\
0 \\
p<0.05\end{array}$ & $\int_{0.005}$ & NS & 0.001 \\
\hline
\end{tabular}

Table 4: Systemic lupus erythematosus disease activity grade and menstrual irregularity

\begin{tabular}{lll}
\hline Group & $\begin{array}{l}\text { Disease activity } \\
\text { Mean grade (SD) }\end{array}$ & $\begin{array}{l}\text { Irregular menses } \\
\text { Number }(\%)\end{array}$ \\
\hline 1 & $2.33(0.49)$ & $4(33)$ \\
2 & $1.6(0.84)$ & 0 \\
3 & - & 0 \\
4 & $\bar{p}<0.05$ & $1(10)$ \\
\hline
\end{tabular}




\section{Discussion}

Dual energy $x$ ray absorptiometry provides a significant advance in the assessment of bone mineral density. When two different photon energies produced by $x$ rays are used the need for soft tissue uniformity is negated. Bone mineral density at proximal and more clinically relevant sites (in terms of the morbidity occurring as a result of osteoporosis), such as lumbar spine and femoral neck, can therefore be measured. Precision is high: the coefficient of variation for the absorptiometry is $1 \%{ }^{8}$ The quality of the final image is thus high. The absorptiometry entails exposing the patient to a very small dose of radiation $(0.003$ millisieverts-equivalent to $1 / 16$ of a modern chest $x$ ray). The procedure causes no discomfort to the patient, and scanning time is short. In addition, once the dual energy $x$ ray absorptiometry is established, the running costs are low. ${ }^{13} 14$

None of the lupus patients taking steroids had evidence on BMD measurement of osteoporosis. There was no significant difference in mean BMD among groups 1,2 , and 4 . Group 1 patients had more active disease than group 2, and had a higher incidence of menstrual irregularity. Mean BMD in group 3 was lower than in groups 1,2 , or 4 , almost achieving the level defined as osteoporotic, but this figure does not reach significance owing to the small number of patients studied.

These results may be interpreted in a number of ways: firstly, a true reduction in BMD in lupus patients taking steroids does exist, and the study population was too small to show this. Secondly, by measuring BMD six months or more into steroid treatment the period when bone mineral loss is maximal might have been missed, as it has been suggested that maximal bone mineral loss occurs early on in the course of steroid treatment. ${ }^{15}$ Possibly, continuing reduction in BMD results in a greater fracture risk than a chronically low BMD. Neither of the two patients in our study with osteoporosis had a history of fracture at any site. Thirdly, all our study subjects were premenopausal, and in general in their early to mid-30s. Under normal circumstances this is about the age at which peak bone mineral density is found. ${ }^{16}$ It may be more relevant to assess the effect of steroids on patients as they approach the menopause, when they are at risk of developing osteoporosis. Finally, lupus patients in general and those receiving steroids in particular are not in fact at risk for the development of osteoporosis. Of these four possibilities, we favour the first or last as most likely.

Study of the natural history of osteoporosis is still at an early stage. Normal ranges of BMD for sections of the British population according to age, sex, and race are currently being finalised. It is not yet clear whether a chronically low BMD or a falling BMD is most important in predisposing to osteoporosis.

As mentioned previously amenorrhoea is associated with more active disease, and this may be the result of weight loss that accompanies systemic illness, or a more complex disturbance of the hypothalamo-pituitary-gonadal axis. Whatever the explanation, amenorrhoea has been shown to be associated significantly with the development of bone mineral loss. ${ }^{17}$

The possibility that lupus patients may be protected from osteoporosis should be considered, in view of work which has shown an aberration of oestrogen metabolism in these patients. ${ }^{18}$ Lahita $e t$ al showed increased rates of 16- $\alpha$ hydroxylation of oestradiol in lupus patients, with the formation of 'oestrogenic' metabolites such as 16- $\alpha$ hydroxyoestrone and oestriol. ${ }^{18}$ These may therefore contribute to the preservation of BMD.

To reach firm conclusions about the effect of oral steroid treatment on the BMD of patients with SLE requires longitudinal studies. These would entail serial monitoring of BMD before and during steroid treatment. It would be important to continue to assess patients as they approached and went through the menopause. This is now possible with minimal risk and inconvenience to the patient, with the advent of dual energy $x$ ray absorptiometry.

We see over 100 patients in our lupus clinic, and, of these, only 12 receiving high dose oral steroids fulfilled the inclusion criteria for this study. Thus any future studies will probably require multicentre participation to obtain meaningful results.

1 Isenberg D A, Morrow W J W. Systemic lupus erythematosus. In: Isenberg D A, Morrow $\mathbb{W} \mathrm{J} W$, eds. Autoimmun rheumatic disease. Oxford: Blackwell Scientific, 1987: 48-147.

2 Wallace D J, Podell T, Weiner J, Klinenberg J R, Forouzeh S, Dubois E L. Systemic lupus erythematosus-survival patterns. Experience with 609 patients. $\mathcal{F A M A} 1981 ; 245$ : 934-8.

3 Dubois E L, Wallace D J. Clinical and laboratory manifestations of systemic lupus erythematosus. In Dubois $\mathbf{E} \mathrm{L}$, ed. tions of systemic lupus erythematosus. In Dubois E L, ed. 413.

4 Tan S L, Jacobs H S. Recent advances in the management of patients with amenorrhoea. Clin Obstet Gynaecol 1985; 12: $725-47$.

5 Selby $\mathbf{P}$ L, Francis R M. Endocrinology and osteoporosis. f Endocrinol 1988; 117: 1-3.

6 Riggs B L, Wahner H W, Melton L J III, Richelson L S, Judd $H$ L, Offord $K$ P. Rates of bone loss in the appendicular and axial skeletons of women: evidence of substantial vertebral bone loss before menopause. $\mathcal{F}$ Clin Invest 1986; 77: 1487-91.

7 Wasnich R D, Ross P D, Maclean C J, Davis J W, Vogel J M. A prospective study of multi-site bone mineral measurements and spine fracture incidence [Abstract]. Calcif Tissue ments and spine fract

8 Cullum I, Ell P J, Ryder J P. X ray dual photon absorptiometry: a new method for the measurement of bone density. Br $\mathcal{Z}$ Radiol 1989; 62: 587-92.

9 Tan E M, Cohen A S, Fries J F, et al. The 1982 revised criteria for the classification of systemic lupus erythematosus. Arthritis Rheum 1982; 25: 1271-7.

10 Isenberg D A, Shoenfeld Y, Schwartz R S. Multiple serologic reactions and their relationship to clinical activity in systemic lupus erythematosus. Arthritis Rheum 1984; 27: $132-8$.

11 Symmonds D P M, Coppock J S, Bacon P A, et al. Development and assessment of a computerised index of clinical disease activity in systemic lupus erythematosus. clinical disease activity in syst

12 Coward D G, Sawyer M B, Whitehead R G. Microtechniques for the automated analysis of serum total protein and for the automated analysis of serum total protein and albumin, urinary urea, creatinine, and hydroxyproline for
nutritional surveys in developing countries. Am $\mathcal{f}$ Clin Nutr nutritional surveys

13 Hall M L, Davies M C, Jacobs H S, Ell P J. Results from first 212 patients studied using QDR bone densitometry [Abstract]. Nucl Med Commun 1989; 10: 217

14 Stein J A, Hohberg A M, Lazewatsky J L. Quantitative digital radiography for bone mineral analysis. In: Dequeker $\mathrm{J} \mathrm{V}$, Gensens $\mathrm{P}$, Wahner $\mathrm{H} \mathrm{W}$, eds. Bone mineral measurements by photon absorptiometry: methodological problems. Leuven: University Press, 1988: 411-4.

15 Reid D M, Kennedy N S J, Smith M A, et al. Bone loss in rheumatoid arthritis and primary generalized osteoarthrosis: effects of corticosteroids, suppressive antirheumatic drugs

16 Nilas L, Christiansen C. Bone mass and its relationship to age and the menopause. $\mathcal{J}$ Clin Endocrinol Metab 1987; 65:

Cann C E, Martin M C, Genant H K, Jaffe R B. Decreased spinal mineral content in amenorrhoeic women. $\mathscr{f A M A}$ spinal mineral co 251 : 626-9.

18 Lahita R G, Bradlow H L, Fishman J, Kunkel H G. Abnormal oestrogen and androgen metabolism in the human with systemic lupus erythematosus. Am $\mathcal{f}$ Kidney Dis 1982; 2 (suppl 1): 206-11. 